\title{
Fortalecimiento
}

\section{de la cooperación financiera regional}

\section{Manuel R. Agosin}

Asesor Económico Regional del Banco Interamericano de Desarrollo (BID) y

Profesor del

Departamento de Economía de la Universidad de Chile manuelag@iadb.org
Las fuertes crisis financieras internacionales que sacudieron a las economías latinoamericanas en los años ochenta y noventa sugieren que el sistema financiero internacional adolece de serios defectos. En este artículo se examina una de las reformas que se han puesto sobre el tapete en años recientes: el fortalecimiento de la cooperación financiera regional. Se llega a la conclusión de que un fondo latinoamericano que contara con una porción modesta de las reservas de los países de la región, reforzadas quizás con créditos contingentes de la banca internacional, podría ser una línea de defensa eficaz contra las crisis financieras ocasionadas por fugas de capitales y contribuir a evitar la propagación por contagio de las crisis dentro de la región. Un fondo de esta naturaleza podría también tener otras funciones, como la de proveer financiamiento para enfrentar problemas de balanza de pagos asociados a deterioros temporarios de los términos del intercambio. Asimismo, un fondo regional contribuiría a la armonización de las políticas macroeconómicas de sus miembros, condición indispensable para lograr una mayor estabilidad en los tipos de cambio bilaterales y una efectiva integración regional. Un fondo regional no sería un sustituto del Fondo Monetario Internacional, sino que más bien lo complementaría. 


\section{I}

\section{Introducción}

Las recurrentes crisis financieras internacionales que han azotado a las economías "emergentes" han dado lugar a un vigoroso debate sobre posibles reformas a la arquitectura financiera internacional. Existen numerosas propuestas de reforma y algunas de ellas incluyen la creación de entidades monetarias regionales (véase Ocampo, 1999, pp. 68-70; Mistry, 1999; FLAR, 2000). En este artículo se analiza la importancia que puede tener el fortalecimiento de la capacidad de los organismos regionales para hacer frente al contagio financiero y para promover el comercio y las inversiones intrarregionales.

Los países latinoamericanos, en particular, han realizado algunos esfuerzos por construir instituciones financieras subregionales que vayan en ayuda de países con problemas de balanza de pagos. También existen en América Latina mecanismos regionales y subregionales de pagos recíprocos cuyo objetivo es reducir la necesidad de recurrir a divisas para financiar pagos entre los países que participan en ellos. Aunque estas instituciones han desempeñado un importante papel en las últimas dos a tres décadas, deben ser fortalecidas para encarar los desafíos de la globalización y para constituirse en el eslabón regional del que carece la arquitectura financiera internacional.

Con el refuerzo de la institucionalidad financiera regional se perseguirían los siguientes objetivos:

i) ayudar a los países miembros a enfrentar crisis de balanza de pagos que ocurren por motivos ajenos a la calidad de sus políticas macroeconómicas;

ii) contribuir a la integración regional promoviendo una mayor estabilidad en los tipos de cambio bilaterales entre los países de la región;

iii) proteger el comercio y las inversiones intrarregionales en momentos de crisis financiera global; iv) proveer un foro que propenda a la coordinación de las políticas macroeconómicas, lo que redundaría en menos vulnerabilidad frente a crisis externas y una mayor estabilidad en los tipos de cambio bilaterales, y

v) promover el intercambio de información sobre temas vitales para la estabilidad financiera internacional, como son las regulaciones prudenciales en el sector financiero y para los flujos de capital.

Se postula en este artículo que la naturaleza de las crisis financieras en el contexto de la globalización de las finanzas aconseja contar con instituciones regionales más fuertes en este campo. La sección II siguiente trata de las crisis financieras de última generación y sus efectos sobre las economías receptoras. La sección III presenta argumentos en favor del fortalecimiento de los mecanismos financieros regionales. En la sección IV se aborda el papel que dichos mecanismos pueden tener en la promoción de la integración regional. En la sección V se describen dos de las instituciones de cooperación financiera internacional existentes en la región: el Fondo Latinoamericano de Reservas (FLAR) y el Convenio de Pagos y Créditos Recíprocos (CPCR) de la Asociación Latinoamericana de Integración (ALADI). La sección VI presenta algunas alternativas para reforzar la institucionalidad financiera regional con miras a enfrentar los desafíos de la globalización financiera y de la integración latinoamericana. En la sección VII se analiza la factibilidad de un fondo regional reforzado y cuál debiera ser el tamaño de dicho fondo para que se le considere capaz de hacer frente a los avatares de la globalización. La sección VIII presenta algunas reflexiones a modo de conclusión. $\square$ El autor agradece los comentarios a versiones anteriores de este trabajo de un árbitro anónimo y de Reinaldo Bajraj, Javier Camboni, Roberto Guarnieri, Felipe Jiménez, Edgard Moncayo, Humberto Mora, José Antonio Ocampo y Rogério Studart. La excelente asistencia de investigación de Ricardo Mayer y Víctor Zúñiga facilitó la preparación del estudio. Este trabajo fue financiado por un proyecto de la CEPAL que contó con recursos del Fondo Latinoamericano de Reservas (FLAR) y de la Corporación Andina de Fomento (CAF). 


\section{II}

\section{Las crisis financieras de última generación}

La crisis financiera internacional que se desató a partir de la depreciación del baht tailandés en julio de 1997 tuvo alcances mundiales y afectó profundamente a los países en desarrollo que habían logrado insertarse en los mercados internacionales de capital. En este contexto, los países de América Latina no pudieron aislar sus economías de los vaivenes de los capitales internacionales. A partir de 1998, la tasa de crecimiento de la región se deterioró sensiblemente y 1999 fue el año de su peor desempeño económico desde la crisis de la deuda.

Más adelante definimos con más precisión el término contagio. Baste decir aquí que consideramos contagio a una perturbación (shock) externa pura que no se relaciona en forma alguna con las bondades o yerros de la política económica interna de los países que la sufren. Por lo general, la expresión contagio se ha aplicado al ámbito financiero: una crisis financiera actúa como señal y esta señal desencadena conductas de manada en los mercados de capitales. Si bien ésta es una de las formas más importantes de contagio en una economía mundial financieramente globalizada, por cierto no es la única. Hay países de América Latina que participan en forma muy parcial en los mercados financieros globales, pero se ven profundamente afectados por los efectos indirectos que los acontecimientos en dichos mercados tienen sobre los términos de su intercambio o el volumen de sus exportaciones. Por estos motivos, usamos el término contagio en un sentido más amplio, que por supuesto también abarca las fugas de capitales causadas por problemas financieros internacionales en otros países o por alzas de las tasas de interés en los países industriales.

Los mecanismos del contagio que experimentó la región durante la crisis financiera mundial más reciente fueron de varios tipos:

i) hubo contagio comercial a través del impacto que tuvo, sobre los términos del intercambio, la recesión en las economías asiáticas (las más fuertemente castigadas por la crisis financiera): los precios de varias materias primas que los países latinoamericanos exportan a los mercados internacionales disminuyeron apreciablemente. Si bien es cierto que la caída de los precios de los productos de exportación fue, en algunos casos, compensada por menores precios de algu- nos productos importados (en particular petróleo y manufacturas), los términos del intercambio de la mayoría de los países se deterioraron; ${ }^{1}$

ii) el contagio comercial también se manifestó a través de la contracción de los volúmenes exportados a Asia, que afectó con particular intensidad a los países para los cuales las economías asiáticas son un mercado importante. Pero el contagio comercial también tomó la forma de una contracción más que proporcional de las exportaciones intrarregionales, las que se concentran en bienes manufacturados;

iii) el contagio financiero fue importante para la mayoría de los países de la región y sus efectos fueron particularmente adversos. Como consecuencia de una corrida de capitales de todos los países emergentes, los bancos y empresas de muchos países de la región tuvieron dificultades para renovar sus líneas de crédito. Los spreads con que pudieron colocarse nuevos bonos corporativos aumentaron dramáticamente. En algunos casos, las empresas de primera línea de la región simplemente no pudieron realizar colocaciones de bonos a ningún precio. Los inversionistas extranjeros de cartera liquidaron sus posiciones;

iv) el contagio financiero tuvo también un aspecto puramente nacional. El aumento repentino del riesgo cambiario motivó a los propios agentes nacionales a trasladar sus inversiones desde papeles en moneda nacional a otros denominados en dólares, lo que agravó la tendencia a la depreciación del tipo de cambio. Las empresas con pasivos en divisas, acumulados durante la larga bonanza de capitales externos, se apresuraron a cubrirse y con ello agudizaron la crisis provocada por la fuga de capitales extranjeros y la no renovación de créditos por parte de la banca internacional;

v) todos los países (a excepción de aquellos que mantienen tipos de cambio fijo) acusaron depreciaciones cambiarias (nominales e incluso reales) excesivas, algunas de las cuales ya se han revertido.

La mayoría de los países de la región sufrieron contagio comercial y también financiero, lo que hizo

\footnotetext{
${ }^{1}$ Este trabajo se terminó de redactar antes de las alzas del precio del petróleo en la segunda mitad de 2000.
} 
que la crisis tuviera efectos tan adversos. Las consecuencias de ambos tipos de contagio pueden ser aminoradas por la vía del financiamiento. En lo comercial, si se espera que el deterioro de los términos del intercambio y/o la caída de los volúmenes exportados sean temporarios y reversibles, la mejor política es obtener financiamiento compensatorio mientras dure el problema. Esta es la razón de ser del Servicio de Financiamiento Compensatorio y Contingente del Fondo Monetario Internacional (FMI).

El contagio financiero también es temporario por naturaleza. Como nos enseñan las crisis de los años noventa (tanto la mexicana como la asiática), las entradas y salidas de capitales se suceden en forma cíclica, tema que abordaremos más adelante con mayor detención. Si el origen del problema de balanza de pagos es el contagio financiero, se justifica contar de antemano con líneas de crédito que complementen las reservas internacionales del país que sufre el problema, evitando así que sus autoridades tengan que aplicar políticas excesivamente restrictivas para reducir el déficit externo.

Dados la globalización de las finanzas, la participación creciente de los países de la región en los mercados internacionales de capital y el comportamiento de los agentes financieros (tanto nacionales como internacionales), es muy probable que las crisis financieras sean cada vez más frecuentes y cada vez más se deban al contagio. Las reformas que se han propuesto a la arquitectura financiera internacional apuntan a reducir la probabilidad de que dichas crisis ocurran y proteger a los países en desarrollo de los peores efectos de las que se produzcan. ${ }^{2}$

Esto implica que las crisis de balanza de pagos que ya están experimentando muchos países pueden tener poco que ver con políticas macroeconómicas desacertadas. Las típicas crisis de balanza de pagos a las que estábamos acostumbrados en la región se originaban en déficit en cuenta corriente que se tornaban no financiables. Las políticas macroeconómicas asociadas a estas crisis incluían elevados déficit fiscales (aun en períodos de auge cíclico) que debían ser monetizados en alguna medida, así como políticas monetarias demasiado expansivas o la insistencia en mantener un tipo de cambio sobrevaluado (quizás porque la inflación interna había sido superior a la internacional

\footnotetext{
${ }^{2}$ Existe una extensa literatura sobre el tema y numerosas propuestas de reforma han sido puestas sobre la mesa. El lector interesado puede consultar Ocampo (1999), Eichengreen (1999), Agosin (1999) y Ahluwalia (2000).
}

por un período suficientemente largo). Políticas macroeconómicas imprudentes llevaban a déficit eventualmente insostenibles en la cuenta corriente y a pérdidas de reservas por parte del Banco Central. Este es el tipo de situaciones con las que el FMI está preparado a lidiar otorgando sus préstamos condicionados.

Por supuesto que la región no está enteramente liberada de estas "crisis de primera generación" (cuya expresión formal como modelo puede encontrarse en Krugman, 1979). Lo que distingue a las crisis actuales es que ellas ocurran en varios países en forma secuencial y muchas veces sin que existan causas evidentes en el manejo macroeconómico de los países afectados. A esto es lo que llamamos "contagio financiero". Como se verá más adelante, esta característica secuencial fue muy evidente en la crisis financiera asiática.

Es una constante empírica que los países que caen presa de esta nueva generación de crisis asociadas con la globalización experimentan primero una poderosa oleada de afluencia de capitales. Es lo que sucedió en México en el período previo a 1994 y ha sucedido en todos los países que han resultado más vapuleados por la reciente crisis financiera: Tailandia, Malasia, Indonesia, Filipinas, la República de Corea, Rusia, Brasil y Argentina. De manera, pues, que en cierto sentido la crisis financiera se gesta durante períodos de excesivas entradas de capital, particularmente de corto plazo (Rodrik y Velasco, 1999). La masiva afluencia de recursos a determinados países obedece a una constelación de factores, entre los cuales figuran la favorable percepción de los inversionistas financieros extranjeros o simplemente las expectativas de que la respectiva moneda se apreciará. ${ }^{3}$ Dado que normalmente las tasas de interés son más altas en mercados emergentes que en los países desarrollados, las expectativas de una apreciación cambiaria pueden desencadenar cuantiosas entradas de capitales.

Esas mismas entradas a menudo no son en absoluto marginales para un receptor individual. En economías emergentes, pueden llegar a representar más del $10 \%$ del producto interno bruto (PIB). Por otra parte, como los mercados financieros de dichas economías son muy poco profundos, los movimientos de capital

\footnotetext{
3 Esta es una versión internacional bastante sui generis de "los concursos de belleza" de Keynes (Eatwell, 1997, p. 243). Así, algunos agentes son más sensibles a lo que otros agentes se proponen hacer que al valor subyacente de los activos. Cuando estos agentes predominan sobre los "fundamentalistas", los mercados financieros pueden tornarse muy volátiles.
} 
con frecuencia constituyen una proporción muy elevada de las finanzas nacionales. Como puede apreciarse en el cuadro 1, mientras en los países desarrollados los movimientos internacionales de capital casi nunca sobrepasan el 5\% de la cantidad de dinero (medida por el M2), en las economías emergentes ellos pueden llegar al $25 \%$.

Por lo tanto, las oleadas de capital pueden provocar importantes externalidades negativas en los países en desarrollo: en efecto, ellas generan déficit en cuenta corriente, aprecian el tipo de cambio, desencadenan burbujas en los precios de los activos y aumentan la vulnerabilidad del sistema financiero nacional a una corrida o no renovación de créditos de corto plazo. Además, a menudo hacen elevarse el coeficiente de deuda de corto plazo a reservas internacionales. A la vez, la naturaleza cortoplacista de las corrientes de capital hace que los inversionistas puedan fácilmente irse en manada del país y los acreedores negarse a renovar sus préstamos tan pronto perciban algún problema.

$\mathrm{Al}$ cambiar las variables económicas fundamentales, en algún momento las percepciones de vulnerabilidad comienzan a crecer y la entrada de capitales a disminuir, pudiendo incluso transformarse en salidas netas, con fugas masivas de recursos. Cuando el país ha perdido cierto volumen de reservas, los inversionistas financieros extranjeros y nacionales descubren

CUADRO 1

Economías desarrolladas y emergentes (14 países): Flujos netos de capital ${ }^{\mathrm{a}}$ a $^{\mathrm{M}}{ }^{\mathrm{b}}$ (Porcentajes)

\begin{tabular}{lccc}
\hline País & 1990-1998 & $1990-1994$ & $1995-1998$ \\
\hline Japón & 1.7 & 1.8 & 1.7 \\
Canadá & 3.1 & 4.2 & 1.7 \\
Estados Unidos & 3.1 & 2.1 & 4.2 \\
Suiza & 5.7 & 5.3 & 6.0 \\
Corea & 5.7 & 4.7 & 7.0 \\
Brasil & 7.2 & 3.3 & 10.4 \\
Indonesia & 9.1 & 8.9 & 8.4 \\
Malasia & 11.2 & 13.2 & 6.3 \\
Venezuela & 14.5 & 18.5 & 11.4 \\
Chile & 18.6 & 18.9 & 19.2 \\
Colombia & 18.5 & 11.8 & 26.0 \\
México & 18.9 & 23.8 & 12.9 \\
Ecuador & 19.6 & 16.4 & 19.3 \\
Argentina & 22.0 & 25.5 & 18.2 \\
\hline
\end{tabular}

Fuente: FMI (2000).

a Entradas o salidas netas (salidas en Suiza y Japón, entradas en otros países).

b Monedas y billetes en circulación, depósitos a la vista, depósitos a plazo y depósitos de ahorro. la existencia de riesgo cambiario, y cuando los temores a la depreciación cobran ímpetu, todos buscan liquidar posiciones en moneda nacional o cubrir sus posiciones pasivas en divisas, acelerando la pérdida de reservas y precipitando una aguda crisis.

Como los bancos fueron grandes receptores de créditos externos durante la bonanza, las salidas de capital están asociadas a la no renovación de créditos y causan profundas crisis bancarias. Por ello, las crisis de última generación suelen ser "crisis gemelas": de balanza de pagos y bancarias al mismo tiempo (Kaminsky y Reinhart, 1996; Kaminsky, Lizondo y Reinhart, 1998).

Cabe recalcar en el contexto actual que tanto las entradas como las salidas de capital están sujetas a contagio. En lo que toca a las entradas, los inversionistas de cartera y los acreedores bancarios tienden a subestimar el riesgo de invertir o de prestar a agentes de la economía receptora. Las entradas de capital a una economía emergente suelen estar acompañadas de entradas a otros países con características similares. Y en momentos de salidas abruptas, se tiende a sobreestimar el riesgo de quedarse en ella (Ocampo, 1999, p. 21). Una gran mayoría de las economías latinoamericanas recibieron ingentes capitales de cartera y préstamos de la banca internacional durante los años noventa. Entre esas economías había algunas que ya habían realizado profundas reformas económicas y otras que estaban iniciando tal proceso (Calvo, Leiderman y Reinhart, 1993; Devlin, Ffrench-Davis y GriffithJones, 1995; Ocampo y Steiner, 1994). Por lo tanto, aunque muchos países habían realizado enormes progresos en su manejo macroeconómico, muchos estaban muy vulnerables al contagio de una estampida financiera como la que ocurrió a partir de la crisis de Asia, la crisis rusa (julio de 1998) y las dos crisis brasileñas (la primera en agosto-septiembre de 1998 y la segunda en enero de 1999).

Ante entradas de capital de gran magnitud en relación con el tamaño de los mercados financieros de las economías receptoras, el manejo macroeconómico en éstas se hace muy complejo. Si bien es posible contrarrestar en algún grado el efecto expansivo de las entradas de capital con políticas fiscales y monetarias restrictivas, ningún país latinoamericano ha sido totalmente exitoso en esta tarea, ni siquiera aquellos que, como Chile y Colombia, se lo propusieron como objetivo explícito de política económica. La experiencia muestra que lo más aconsejable para las economías emergentes son las regulaciones prudenciales sobre las corrientes de capitales. 
Aunque hay evidencia de que algunas formas de contagio financiero son simultáneas (ampliación simultánea de los spreads que deben pagar los deudores de economías emergentes, por ejemplo), la experiencia de los últimos años indica que las crisis financieras internacionales ocurren en forma secuencial. Luego que una economía comienza a experimentar salidas de capital, los inversionistas y acreedores internacionales empiezan a dudar de la solvencia de deudores en otros países que podrían presentar síntomas parecidos. En algunos casos, el contagio es fruto de los efectos de la crisis inicial: la depreciación cambiaria que resulta de la primera crisis torna menos competitivas las exportaciones de otras economías con perfiles de exportación parecidos.

\section{III}

\section{El papel de los fondos regionales ante las crisis financieras}

Como ya afirmamos al principio de este artículo, los fenómenos que describimos han hecho cundir la percepción de que la arquitectura financiera internacional necesita importantes modificaciones y ha suscitado un debate internacional muy interesante acerca de cuáles debieran ser los elementos constitutivos de esa nueva estructura. Uno de ellos es el de asignar una importancia mucho mayor a las instituciones monetarias regionales como línea adicional de contención de las crisis financieras y del contagio.

El objetivo de fortalecer la institucionalidad financiera regional no significa sustituir al FMI, institución clave en el sistema monetario internacional. Ningún fondo regional contaría ni con el volumen de recursos del FMI ni con la capacidad política para movilizar rescates financieros de gran envergadura cuando ellos fueran necesarios. Por lo demás, muchos problemas financieros internacionales rebasan el ámbito regional y requieren de soluciones globales.

Los fondos regionales pueden constituirse en un vínculo importante entre países individuales y un FMI fortalecido y reformado, dotando así al sistema de una mayor capacidad para promover la estabilidad financiera internacional. Y si la reforma a nivel internacional no se diera, con más razón aún se justificaría que los países latinoamericanos reforzaran sus líneas de defensa frente a las crisis financieras mediante el fortalecimiento de la cooperación regional.

Las razones para reforzar los fondos regionales son varias. Todos los países latinoamericanos están continuamente expuestos a perturbaciones externas temporarias, ya sea por fluctuaciones en la relación de precios de su intercambio, elevaciones en las tasas de interés en los mercados financieros internacionales, o perturbaciones financieras como las descritas más arriba. Estas perturbaciones pueden enfrentarse de diversas maneras. Una de ellas es el autoaseguro, que consiste en mantener niveles de reservas internacionales más elevadas que las actuales o contratar líneas de crédito contingentes con la banca internacional. Esta solución entraña dos problemas: el costo de oportunidad de las reservas es elevado y los créditos contingentes de la banca privada internacional con que puede contar cada país son costosos y modestos. Una segunda opción es recurrir directamente al FMI. Los países latinoamericanos, sin duda, seguirán haciéndolo cuando enfrenten severas dificultades financieras; pero el Fondo suele imponer condiciones que no siempre son adecuadas para enfrentar el problema y sus decisiones suelen ser demasiado lentas para lidiar con situaciones que requieren una capacidad de respuesta rápida. Por último, los países latinoamericanos tienen escasísima influencia sobre las decisiones y criterios del FMI.

Por todas estas razones, recurrir a un organismo regional puede ser una opción atractiva. Una entidad monetaria regional puede responder de manera eficaz a problemas netamente regionales. La conveniencia de contar con reservas adecuadas para hacer frente a problemas comunes es, entonces, un argumento poderoso en favor de establecer lo que sería en efecto una cooperativa de crédito internacional en la región. $\mathrm{Si}$, además, las crisis financieras tienen un componente de contagio regional, el argumento a favor de la constitución de fondos regionales para hacerles frente se torna aun más poderoso, particularmente si al evitar una crisis de balanza de pagos en un país de una región determinada se estuvieran evitando crisis similares en otros países de 
la misma región. En otras palabras, un organismo financiero regional tendría externalidades importantes.

El contagio regional fue claramente visible durante la crisis financiera más reciente, que tuvo dos fases, ambas con un fuerte contenido regional. La primera fue netamente asiática; comenzó en julio de 1997 en Tailandia y en la segunda mitad del año se extendió gradualmente y, en forma secuencial, a casi todos los mercados emergentes del Asia: Indonesia, Filipinas, Malasia, la región administrativa de Hong Kong, la provincia china de Taiwán, Singapur y, finalmente, a la República de Corea en noviembre del mismo año. Cayeron justos y pecadores: países con deudas de corto plazo elevadas en relación con sus reservas (Tailandia, Indonesia, Malasia y la República de Corea) y economías con una situación de reservas muy sólida (Hong Kong y Singapur); países con elevados déficit en cuenta corriente como proporción del PIB (Tailandia y Malasia), países con déficit moderados (República de Corea e Indonesia) e, incluso, economías con superávit significativos (Singapur y Hong Kong).

En 1998, después de la crisis rusa, el real brasileño debió soportar el primer ataque especulativo en agosto y septiembre. Esto exacerbó la crisis en América Latina, región que ya estaba experimentando dificultades comerciales y financieras importantes pero aún manejables. Ya a mediados de 1998, con la estampida de los inversionistas de cartera desde los países emergentes y la reevaluación negativa de los deudores latinoamericanos por los acreedores internacionales, los países de la región habían comenzado a tener graves problemas de balanza de pagos que requirieron severas políticas de ajuste. Pero fue el segundo, y exi- toso, ataque especulativo en contra del real, en enero de 1999, lo que desató la crisis en su fase más aguda en los demás países de la región.

$\mathrm{Si}$ las crisis financieras no fueran secuenciales, es poco probable que un fondo regional pudiese contar con recursos suficientes para enfrentar fugas de capital desde varios países al mismo tiempo. Como estas crisis sí pueden ocurrir (la crisis de la deuda durante los años ochenta fue un señalado ejemplo), el papel de una institución como el FMI en la resolución de tales crisis no puede ser desempeñado por fondos regionales.

Si las crisis se van extendiendo gradualmente de una economía a otra, un fondo regional capaz de detener la fuga de capitales desde el primer país de la región que se viese afectado reduciría significativamente los riesgos para los demás países de la región. Por supuesto, suponiendo que la causa de la crisis inicial no es el mal manejo macroeconómico. Para corregir esto último, un mecanismo regional diseñado con miras a controlar fenómenos de contagio no es la solución adecuada. Sólo lo es la provisión internacional de liquidez bajo una condicionalidad apropiada.

Los fondos regionales se justifican también por otros motivos. Los países de una región tendrán mucho más que decir sobre las políticas de un fondo regional que sobre las políticas de un organismo como el FMI. Por lo tanto, un fondo regional respondería a las necesidades de los países que lo constituyen de manera mucho más cabal. Esto puede ser muy importante a la hora de coordinar políticas monetarias y económicas para alcanzar un estadio de integración regional más avanzado, tema que abordaremos en la próxima sección.

\section{IV}

\section{El papel de los fondos regionales en favor de la integración}

La necesidad de fortalecer la cooperación financiera regional va más allá de la defensa común frente a fenómenos de contagio. La integración regional es un objetivo privilegiado de la política de desarrollo de todos los países latinoamericanos. En años recientes ha habido importantes avances en los aspectos comerciales de la integración, tanto en el marco de los acuerdos plurilaterales de integración existentes en Améri- ca Latina - el Mercosur, la Comunidad Andina, el Mercado Común Centroamericano (MCCA), la Comunidad del Caribe (Caricom) - como entre países individuales. Asimismo, desde el comienzo de los años noventa se han celebrado numerosos acuerdos comerciales bilaterales bastante completos. Tanto los acuerdos plurilaterales como los bilaterales han contribuido a elevar significativamente el comercio intrarregional, 
que ha aumentado a tasas más aceleradas que el interregional.

Sin embargo, la falta de armonización de las políticas macroeconómicas y las agudas fluctuaciones de los tipos de cambio bilaterales están conspirando contra un avance más decisivo hacia la integración comercial y las inversiones recíprocas entre los países de la región. En la Comunidad Andina, a raíz de la crisis financiera, el fuerte crecimiento del comercio recíproco de los últimos años se detuvo bruscamente en 1998.

Hasta el momento, los gobiernos han actuado bajo el supuesto implícito de que es posible avanzar hacia la integración comercial ocupándose principalmente de rebajar aranceles y desmantelar barreras no arancelarias al comercio y dejando para una etapa posterior los temas cambiarios y financieros. Quizás sea hora de invertir el proceso. La experiencia ha demostrado una y otra vez que la volatilidad del tipo de cambio y las crisis financieras desarticulan las corrientes de comercio y terminan desarmando, en la práctica, el andamiaje formal de los acuerdos comerciales. Una crisis financiera internacional puede hacer variar repentinamente el tipo de cambio de un país con respecto a los de sus socios regionales en un porcentaje mucho mayor que su arancel de nación más favorecida. Esto nos indica que la estabilidad cambiaria bilateral puede ser más importante que la reducción arancelaria para incentivar los flujos comerciales regionales y subregionales.

El propio Mercosur, el proceso de integración subregional más ambicioso de los últimos tiempos, ha sido sometido a considerables presiones precisamente por la inestabilidad del tipo de cambio entre sus dos socios más grandes, debido al impacto sobre las economías nacionales de los cambios de dirección de los movimientos de capital y a la falta de coordinación macroeconómica y cambiaria entre los países.

Las razones por las cuales las crisis financieras son tan dañinas para el comercio recíproco son varias. Ante todo, cuando un país empieza a experimentar problemas de balanza de pagos, ocurren dos fenómenos: se deprecia su tipo de cambio frente a las monedas de sus vecinos y cae la demanda agregada. Este último efecto puede ser amplificado por la adopción de políticas restrictivas orientadas a enfrentar la crisis de balanza de pagos. Los efectos comerciales recaen en forma particularmente aguda sobre los países vecinos, los cuales encuentran más dificultades para vender sus productos en el mercado del país en crisis y, a la vez, deben enfrentar una mayor competencia proveniente de las exportaciones de este último.
El comercio intrarregional en América Latina está fuertemente concentrado en manufacturas, cuya demanda es muy sensible a las fluctuaciones de los tipos de cambio y de la demanda agregada de los socios. No sucede lo mismo en el comercio de productos básicos, los que se exportan fundamentalmente a los países industriales.

La inestabilidad de los flujos financieros que se dirigen a los países de América Latina produce una gran volatilidad en los tipos de cambio bilaterales en su interior y deprime la actividad económica en todos ellos. Estos dos factores son muy perjudiciales para el logro de una integración económica más estrecha.

Las crisis financieras generalizadas son particularmente dañinas para la integración. Cuando un país comienza a contagiarse de otras crisis dentro de la región, se deprecia su moneda y sus productores recuperan la competitividad perdida durante el auge de capitales que precedió a la crisis. Sin embargo, los efectos positivos de la depreciación cambiaria se logran a expensas de sus socios regionales. Además, no puede cosechar todos sus frutos porque, como resultado de la crisis, los socios regionales están sufriendo una recesión. Los cambios abruptos en la competitividad de los productores brasileños comparada con la de los argentinos durante la reciente crisis financiera son un ejemplo paradigmático.

Es indudable, entonces, que para alcanzar una mayor integración comercial y de las inversiones se requiere una mayor estabilidad cambiaria entre los países que buscan integrarse. Sin ella, es poco probable que en la región se logre seguir avanzando hacia una integración mucho mayor. Ello no significa que se deba ir rápidamente a la adopción de una moneda común. Los procesos de integración se desarrollan gradualmente y en América Latina están aún en sus comienzos. Pero es indispensable dar los primeros pasos hacia la integración financiera, para lo cual los tipos de cambio bilaterales deben tener mucho más estabilidad que la que han exhibido hasta ahora.

Baste recordar la experiencia europea. Toda la primera etapa de la integración europea se dio en el marco de la estabilidad cambiaria que le otorgaba el régimen de tipos de cambio fijos (pero ajustables) surgido de Bretton Woods. Cuando dicho régimen se desintegró en 1971-1973, buena parte del trabajo para establecer una unión aduanera ya se había hecho. No obstante, los miembros de la Comunidad Económica Europea rápidamente lograron dotar a sus tipos de cambios bilaterales de un grado de estabilidad que no se habría dado si se hubieran decidido a emplear el 
régimen que comenzó a imperar a partir de 1973 para las monedas convertibles: tipo de cambio flexible con flotación sucia. Los países europeos decidieron primero que sus monedas flotaran juntas en lo que se denominó "la serpiente", que limitaba las fluctuaciones de los tipos de cambios bilaterales. Luego, adoptaron el Sistema Monetario Europeo (SME), con su Mecanismo de Tipos de Cambio (MTC), que fijaba un tipo de cambio central para cada moneda con respecto a la Unidad Monetaria Europea (el ECU) y bandas de flotación estrechas alrededor del tipo de cambio central. La etapa final fue alcanzada a comienzos de 1999 con el establecimiento del euro.

Los embates que recibió el MTC durante las crisis financieras de 1992-1993 no impidieron el avance definitivo hacia la fijación irrevocable de los tipos de cambio y la adopción del euro por 11 países europeos. No cabe duda de que la estabilidad cambiaria entre países europeos, con la que ellos se comprometieron políticamente, dio un fuerte impulso a la integración comercial y a los flujos de inversión real en Europa.

La existencia de instituciones monetarias comunitarias y la intervención concertada en los mercados cambiarios ayudaron a los países europeos a alcanzar el alto grado de estabilidad cambiaria que han experimentado desde el colapso del sistema de Bretton Woods.

Una de las diferencias cruciales entre los países que componen la Unión Europea y los países latinoamericanos es que los primeros poseen monedas convertibles y pueden realizar intervenciones en los mercados cambiarios en sus propias monedas. Además, sus bancos centrales (y ahora el Banco Central Europeo) cuentan con líneas de crédito de la Reserva Federal de los Estados Unidos y del Banco de Japón, con el fin de intervenir en los mercados cambiarios.

Los países latinoamericanos están en fuerte desventaja en estos aspectos, ya que, al ser la moneda de intervención el dólar estadounidense, deben recurrir a sus reservas; la intervención coordinada de bancos centrales es mucho menos poderosa para impedir fuertes fluctuaciones y desalineamientos en los tipos de cambio bilaterales. Tampoco cuentan con líneas de crédito de la Reserva Federal. Sólo en tiempos de crisis, y únicamente los países más grandes, pueden tener algún éxito en conseguir recursos financieros de emergencia de esa fuente. Por lo demás, esto ocurre sólo una vez que se ha desatado una crisis y en el marco de un programa de ajuste acordado con el FMI.
Todo esto sugiere que el apoyo monetario y cambiario a la integración sólo vendrá de una institucionalidad financiera regional más completa que la que existe hoy en día. Para que América Latina pueda alcanzar una mayor integración comercial, es importante que se logre una mayor estabilidad de los tipos de cambio entre los países de la región, la que también incentivaría el crecimiento de las inversiones recíprocas, en un proceso que ya ha comenzado y que resulta indispensable para llegar a una integración económica más completa.

Desde luego, los objetivos de contar con recursos financieros para limitar los fenómenos de contagio a nivel regional o subregional y de dar mayor estabilidad a los tipos de cambio bilaterales están relacionados. Las crisis financieras tienen un efecto casi inmediato sobre el tipo de cambio. Por lo tanto, si una institución financiera regional cumple con el objetivo de evitar las crisis financieras en los países miembros contribuirá asimismo a una mayor estabilidad cambiaria entre ellos.

Los tipos de cambio también responden a desalineamientos de las políticas económicas. Por lo tanto, al promover una mayor convergencia de las políticas macroeconómicas, la existencia de una institución financiera regional acotaría la volatilidad cambiaria entre los países miembros.

Como ya se ha anotado más atrás, las crisis financieras se gestan durante las bonanzas de capitales externos. Para evitar tales crisis es indispensable que los países tomen medidas para moderar las entradas de capitales cuando ellas amenazan con ser excesivas y con deteriorar sus equilibrios macroeconómicos. Una de las misiones de una institución financiera regional sería la de facilitar el intercambio de información y así propiciar estándares comunes para la regulación bancaria y para la regulación prudencial de las corrientes de capitales. ${ }^{4}$ Porque las entradas de capital desestabilizadoras incluyen flujos no intermediados por la banca (préstamos directos a empresas nacionales y entradas de cartera), estas regulaciones prudenciales tienen relación no sólo con una adecuada supervisión bancaria, aunque por supuesto es esencial.

\footnotetext{
${ }^{4}$ La experiencia reciente de Chile y Colombia, en este campo, ha sido analizada en Agosin y Ffrench-Davis (1997), Le Fort y Lehmann (2000), Barrera y Cárdenas (1997) y Ocampo y Tovar (1999).
} 
V

\section{Breve examen de algunas instituciones regionales de apoyo a los pagos externos}

América Latina cuenta ya con instituciones financieras y monetarias que cumplen parcialmente algunas de las funciones que le estamos asignando a un fondo regional. Ellas son el Fondo Latinoamericano de Reservas (FlaR), el Convenio de Pagos y Créditos Recíprocos (CPCR) de la Asociación Latinoamericana de Integración (ALADI), la Cámara de Compensación Centroamericana del MCCA, el Fondo Latinoamericano de Estabilización Monetaria del MCCA y el Caribbean Multilateral Clearing Facility de la Caricom. ${ }^{5}$ Por lo tanto, un buen punto de partida es el análisis de sus actividades y de los montos de financiamiento que estos organismos otorgan. Aquí concentraremos nuestra atención en dos de estas instituciones: el FLAR y el CPCR.

\section{El Fondo Latinoamericano de Reservas (FLAR)}

El FlAR fue creado en 1978 por la Comunidad Andina como Fondo Andino de Reservas. En 1991 sus miembros (Bolivia, Colombia, Ecuador, Perú y Venezuela) decidieron abrirlo a la participación de otros países latinoamericanos, convirtiéndolo de jure en una institución financiera regional. A fines de junio de 1998, el FLAR tenía un patrimonio de unos 1032 millones de dólares, constituido por las cuotas de los países miembros y por sus ganancias netas capitalizadas (FLAR, 1998). Con la incorporación de Costa Rica a mediados de 2000, el FLAR inició un proceso de ampliación hacia países latinoamericanos que no son miembros de la Comunidad Andina, con miras a darle mayor alcance (FLAR, 2000).

Los objetivos explícitos del FLAR son:

- Apoyar a los países miembros cuando enfrenten problemas de balanza de pagos.

- Contribuir a armonizar políticas macroeconómicas y cambiarias, con el fin de apoyar a los países en el cumplimiento de los compromisos asumidos en el Acuerdo de Cartagena, que creó la Comunidad Andina, y el Tratado de Montevideo, que estableció la ALADI.

\footnotetext{
${ }^{5}$ Véase en CEPAL (1990) una descripción de otros mecanismos de cooperación financiera en la región.
}

- Mejorar las condiciones de inversión para las reservas internacionales de los países miembros.

El FLAR se financia fundamentalmente con cuotas de los bancos centrales de los países miembros. Otra modalidad para captar fondos es la aceptación de depósitos a plazo de los bancos centrales y de otras entidades autorizadas. Durante el año financiero 1997/1998 (1 de julio de 1997 a 30 de junio de 1998), los bancos centrales y el Parlamento Andino constituyeron depósitos por 1837 millones de dólares, con un saldo al 30 de junio de 1998 de 237 millones (FLAR, 1998).

La principal actividad del FLAR es la de prestar servicios de apoyo a las balanzas de pagos de los países miembros. De hecho, el FLAR ya es una cooperativa de crédito al estilo del FMI. Los bancos centrales de dichos países pueden girar préstamos que son hasta dos veces y media el valor del aporte de capital pagado, en el caso de Colombia, Perú y Venezuela, y hasta tres veces y media en el caso de Bolivia y Ecuador.

El FLAR provee los siguientes servicios a los bancos centrales de los países miembros:

- Créditos de apoyo a las balanzas de pagos: Se conceden hasta por cuatro años, incluyendo un año de gracia, con compromisos de desempeño macroeconómico.

- Créditos a la reestructuración de la deuda pública externa: Se otorgan en condiciones de cofinanciamiento con otros organismos multilaterales, con un plazo de hasta cuatro años, incluyendo un año de gracia.

- Créditos de liquidez: Tienen por objeto ayudar a los países a cubrir necesidades transitorias de liquidez con créditos de hasta un año de duración.

- Servicio de Financiamiento Contingente: Creado en 1998, este servicio ayuda a los países miembros a financiar desequilibrios de balanza de pagos temporales y de origen externo no relacionados con una inconsistencia fundamental de las condiciones de equilibrio de la balanza de pagos. El plazo de este financiamiento es de seis meses no renovables. Los préstamos otorgados por este servicio deben estar garantizados por los deudores con títulos aceptables para el FLAR. 
- El peso andino: Fue creado para facilitar pagos entre bancos centrales y otros tenedores autorizados. Ha sido poco utilizado hasta ahora.

Ciertamente, el FLAR cubre casi toda la gama de actividades que desearíamos para un fondo regional fortalecido. ¿Cuán importante es desde un punto de vista cuantitativo el financiamiento que entrega a los bancos centrales de los países miembros para evitar o paliar crisis de balanza de pagos, particularmente las que se producen por motivos exógenos, y su contribución a la estabilidad de los tipos de cambio bilaterales?

La relevancia del FLAR como proveedor de financiamiento depende de sus cuotas, que son su única fuente de financiamiento estable. Como puede apreciarse en el cuadro 2, las cuotas en el FLAR de los países miembros, salvo Venezuela, son significativas con respecto al monto de sus cuotas en el FMI. Además, el acceso a los recursos del FLAR multiplica el valor de las cuotas hasta en 3.5 veces para los países miembros menos desarrollados (Bolivia y Ecuador) y en 2.5 veces para los otros tres. Vale decir, Bolivia y Ecuador tienen acceso a préstamos del FLAR por 437.5 millones de dólares, cifra considerablemente superior a la que podrían obtener del FMI, el que rara vez otorga créditos superiores al tamaño de la cuota y, cuando lo hace, ellos son fraccionados (en tranches), de lento desembolso y contra prueba de que el deudor está cumpliendo con las condiciones establecidas en la carta de intención. Los préstamos del FLAR no están exentos de condicionalidad, pero ella tiende a ser menos estricta. Los desembolsos pueden ser bastante rápidos, mediando sólo una reunión de directorio entre una solicitud para girar montos superiores a la cuota y el otorgamiento del crédito.
Para los países miembros más pequeños, los créditos disponibles del FLAR representan una adición importante a sus reservas y a su capacidad para hacer frente a una crisis financiera internacional. Para los tres de mayor tamaño, esto no es así: sus reservas internacionales son un múltiplo elevado de sus cuotas en el FLAR.

La relación entre la deuda de corto plazo y las reservas internacionales suele ser considerada un indicador certero de la vulnerabilidad a una corrida en contra de la moneda de un país. En el cuadro 2 hemos realizado dos cálculos: la razón entre la deuda de corto plazo y las reservas imperante a fines de 1997 y la razón deuda/reservas incluyendo el máximo de crédito disponible del FlAR. Como puede verse en el cuadro, el acceso a los recursos del FLAR disminuye significativamente la vulnerabilidad externa de Bolivia y Ecuador, aunque no la de los países más grandes.

Con todo, y a pesar de sus modestos recursos, el FLAR ya está desempeñando un papel importante en las finanzas internacionales de los países de la Comunidad Andina. Sin embargo, para que el FLAR o un sucesor con capacidades ampliadas se transforme en una institución capaz de proveer el financiamiento que necesitan los países miembros, tendrá que disponer de recursos bastante más cuantiosos. En la sección VI proponemos diversas maneras de lograrlo.

\section{El Convenio de Pagos y Créditos Recíprocos de la ALADI (CPCR)}

El CPCR comenzó a operar en 1969 y tiene la finalidad de minimizar el uso de las reservas internacionales en la liquidación de pagos por operaciones de comercio exterior entre los miembros de la ALADI. El sistema

CUADRO 2

Fondo Latinoamericano de Reservas (FLAR): Indicadores de tamaño relativo de las cuotas, fines de 1997

(Millones de dólares; razones en porcentajes)

\begin{tabular}{lrrrrr}
\hline & Bolivia & Colombia & Ecuador & Perú & Venezuela \\
\hline Cuotas FLAR & 125 & 250 & 125 & 250 & 250 \\
Cuotas FMI & 170 & 757 & 296 & 628 & 2633 \\
Reservas internacionales & 1359 & 9611 & 2213 & 11306 & 17704 \\
$\begin{array}{l}\text { Deuda corto plazo } \\
\begin{array}{l}\text { Deuda/reservas } \\
\text { Deuda/reservas }\end{array}\end{array} \quad 374$ & 5759 & 2069 & 632 & 4395 \\
$\quad$ aumentadas por FLAR & 27.5 & 59.9 & 93.5 & 60.4 & 24.8 \\
\hline
\end{tabular}

Fuente: FMI (1998); Banco Mundial (1999); FLAR (1998).

a Razón deuda de corto plazo/reservas.

b Razón deuda de corto plazo/reservas más el máximo de endeudamiento con el FLAR. 
tiene dos componentes: una cámara de compensación, con el Banco Central de la Reserva del Perú como banco agente, y líneas de crédito recíproco con vencimientos cuatrimestrales. El banco agente efectúa las compensaciones entre acreedores y deudores en forma cuatrimestral. Los bancos centrales se han otorgado líneas de crédito bilaterales en dólares que también deben ser liquidadas cada cuatro meses. El sistema ha sido exitoso, por cuanto un porcentaje elevado y creciente del comercio intrarregional ha sido cubierto por sus operaciones (CEPAL, 1990). En 1990, la cobertura de las operaciones cursadas por el convenio en relación con el valor del comercio intrarregional fue casi del $100 \%$. Por otra parte, las divisas transferidas por el banco agente constituyeron menos del $20 \%$ del valor de las transacciones. Por lo tanto, la existencia del CPCR ha significado un importante ahorro de divisas para los bancos centrales de los países miembros de la ALADI.

El sistema fue puesto a prueba durante la crisis de los años ochenta. A causa de dicha crisis, algunos bancos centrales experimentaron dificultades para cubrir sus saldos deudores y debieron salir del sistema, negociando bilateralmente condiciones de pago con los bancos centrales acreedores. A medida que la crisis financiera fue amainando, los bancos centrales volvieron al sistema, el cual ya había recuperado a todos sus miembros en 1988.

El Acuerdo de Santo Domingo de 1981 creó un mecanismo para extender crédito a bancos centrales que se viesen impedidos de liquidar sus saldos deudores en el período de cuatro meses. El plazo de este financiamiento es de cuatro meses adicionales, renovables hasta por un año. El Acuerdo estableció un programa de crédito especial para países que experimenten déficit generales de balanza de pagos y para países que estén enfrentando catástrofes naturales. Para los primeros, el plazo es de dos años, renovable por un año adicional. Para los segundos, el plazo es de dos años, renovable bilateralmente con los bancos centrales acreedores por cinco años.

A diferencia del FLAR, el CPCR no posee recursos propios, sino que debe hacer efectivas las líneas de crédito a las que se han comprometido los bancos centrales. Al generalizarse la crisis regional, éstos no estuvieron en condiciones de enterar los aportes a los que se habían comprometido. Es por ello que se hace indispensable que se maneje un sistema de pagos en conjunción con una institución regional de mayor volumen y peso financiero.

\section{VI}

\section{Opciones para fortalecer los organismos} regionales de pagos

El FLAR es ciertamente un buen punto de partida para una institucionalidad financiera regional fortalecida: sus operaciones son ya de una dimensión significativa y las funciones que los países miembros le han asignado son precisamente las que debe tener un mecanismo financiero regional. En esta sección abordamos varios aspectos que deberían tenerse en cuenta en un escenario en que los países de la región acuerden la creación de una institución financiera latinoamericana. ${ }^{6}$

\footnotetext{
${ }^{6}$ No estamos sugiriendo que el FLAR deba, necesariamente, convertirse en el organismo monetario regional fortalecido por el que se aboga en este artículo. Las modalidades para pasar de la institucionalidad existente a una con mayores recursos y capacidad de acción es un tema político que rebasa el marco de este trabajo. El objetivo de esta sección es esbozar las características que debería tener un futuro organismo financiero de alcance continental.
}

\section{Miembros}

El fondo regional estaría abierto a todos los países de América Latina y el Caribe. La participación en un fondo regional de las características del FLAR puede resultar muy atractiva. Las reservas depositadas en él se multiplican en caso de crisis. Además, el fondo podría acceder a recursos a los que no tendrían acceso los países por sí solos.

\section{Recursos}

Los recursos con que cuente un fondo regional deben ser de una magnitud que se condiga con su misión. Para ello existen varias opciones: 


\section{a) Aumentos en el capital pagado del fondo}

$\mathrm{Al}$ ingresar nuevos miembros, aumentarían los recursos del fondo. También se puede pensar en elevar las cuotas, que hoy representan entre el 9 y el $1.5 \%$ de las reservas de los miembros del FLAR.

\section{b) Compromisos contingentes de crédito}

Los bancos centrales miembros podrían otorgar líneas de crédito al fondo que se activaran sólo en casos de emergencias financieras de características preestablecidas. Esta solución sería similar a los $G e$ neral Arrangements to Borrow (GAB) y los New Arrangements to Borrow (NAB) entre el Fondo Monetario Internacional y los bancos centrales del Grupo de los 10 y de Suiza. Además, el Fmi tiene un acuerdo paralelo con Arabia Saudita. Bajo el GAB, 11 países industriales o sus bancos centrales han acordado prestar al Fondo ciertos volúmenes de recursos a tasas de interés de mercado, en situaciones de crisis financiera que no puedan ser abordadas con los recursos normales del FMI. Aprobado en noviembre de 1994 a raíz de la crisis mexicana, el NAB es similar, excepto que en él participan 25 países. Los recursos a los que tiene acceso el FMI bajo ambos acuerdos pueden ser prestados tanto a países participantes como a no participantes. Un mecanismo de este tipo dotaría al fondo latinoamericano de recursos muy superiores a su capital, para enfrentar emergencias financieras en los países miembros.

\section{c) Endeudamiento en los mercados internacionales de capital \\ El FMI no está autorizado a endeudarse para fi-} nanciar sus operaciones de asistencia a países que sufren crisis financieras. Pero no hay impedimentos para que un organismo latinoamericano lo haga. El fondo latinoamericano podría emular al Banco Mundial y tener dos clases de capital: uno estaría constituido por las cuotas de los bancos centrales y el otro serviría de garantía para que el fondo se endeudara directamente en los mercados. Esta opción es aún conservadora, ya que la razón de apalancamiento (gearing ratio) del fondo, incluso bajo esta modalidad, sería inferior a 1.

¿Estarían dispuestos los mercados financieros internacionales a aceptar bonos de largo plazo de un fondo latinoamericano y sería menor el spread otorgado a los papeles del Fondo que el que deben cancelar sus países miembros? La respuesta a ambas preguntas es probablemente sí: la garantía de todos los miembros del fondo en forma conjunta debe ser superior a la de cada uno por separado, ya que la capacidad financiera de un grupo de países actuando concerta- damente es superior a la que tienen en forma independiente. ${ }^{7}$

$\mathrm{Al}$ aumentar la disponibilidad de recursos financieros, esta opción le daría al fondo una gran capacidad para ayudar a los países miembros que enfrentaran problemas financieros.

\section{d) Créditos contingentes con la banca privada}

El fondo podría negociar líneas de crédito con la banca privada internacional que se activarían en situaciones de crisis financieras que amenazaran a países miembros. Los bancos centrales de Argentina y México ya lo han hecho en forma individual. Sin duda, la intervención de un organismo regional podría ayudar a conseguir mayores volúmenes de recursos y mejores condiciones, ya que estaría respaldada por todos los bancos centrales o gobiernos de los países miembros. Esta opción, junto con la discutida en el acápite anterior, podría hacer que el fondo fuese atractivo aun para países grandes con necesidades financieras en períodos de crisis, que podrían rebasar la capacidad del fondo.

\section{e) Creación de un "derecho especial de giro latino- americano"}

El FLAR ya cuenta con una figura de esta naturaleza: el peso andino. Pero ciertamente tendría más usos un peso latinoamericano, que podría utilizarse en pagos entre bancos centrales de la región. Una unidad contable de esta naturaleza podría reforzar el CPCR y ayudar a economizar en el uso de las reservas internacionales.

Tal como en el FMI, los países miembros y el CPCR recibirían asignaciones de pesos latinoamericanos que podrían ser utilizados en los pagos entre bancos centrales para liquidar posiciones deudoras en el CPCR. Los países que hicieran uso neto de pesos latinoamericanos se comprometerían a redimir los saldos deudores netos cuando su situación de balanza de pagos mejorara o en plazos máximos que determinaría el directorio del FLAR. Está claro que esta opción involucra una estrecha relación entre el CPCR y el fondo. Sería posible que el CPCR pasara directamente a constituir un servicio del fondo.

\footnotetext{
7 Se podría argumentar que el spread que debería pagar el fondo sería un promedio ponderado de los spreads sobre la deuda soberana de sus integrantes. Estamos asumiendo que el fondo tendría una sinergia importante por tratarse de una institución con garantías simultáneas de un grupo de países. En este sentido, la existencia del fondo podría entenderse como la solución a un problema de acción colectiva.
} 


\section{f) Acceso a los recursos del FMI}

$\mathrm{Si}$ el fortalecimiento de la institucionalidad regional ocurriera en el contexto de una reforma a la arquitectura financiera internacional que contemplara la creación de una red de fondos regionales para complementar al FMI en caso de crisis que afectaran a varios países de la región, el fondo latinoamericano, así como otros, podría intermediar recursos entre el FMI y los países afectados (Ocampo, 1999, p. 70). Asimismo, el fondo latinoamericano podría ser designado como receptor de derechos especiales de giro (DEG), a los que podría echar mano en tiempos de crisis. ${ }^{8}$

\section{Los posibles servicios del fondo y su condicio- nalidad}

Es necesario establecer en forma clara las ocasiones en que un país que experimentara problemas de balanza de pagos podría acudir al fondo. Así, cabría distinguir cuatro tipos de problemas de balanza de pagos: (a) escasez temporaria de liquidez internacional; (b) crisis de balanza de pagos debidas a desequilibrios fundamentales en la política económica del país miembro; (c) crisis de balanza de pagos por contagio, y (d) problemas de balanza de pagos por deterioro transitorio en los términos del intercambio.

\section{a) Servicio de créditos de liquidez}

El FLAR ya cuenta con un servicio para enfrentar problemas transitorios de liquidez. Los países pueden hacer uso de una proporción de sus cuotas $(75 \%$ en el caso de los dos países miembros de menor desarrollo relativo, $50 \%$ en el caso de los otros tres) por períodos de un año. Una institución monetaria latinoamericana podría incorporar este mismo servicio sin mayores alteraciones.

\section{b) Servicio de créditos de apoyo a la balanza de pagos}

Este servicio estaría disponible para aquellos países que experimentasen problemas de balanza de pagos por razones de desequilibrio fundamental en sus políticas económicas (cambiarias, monetarias y fiscales). Estos créditos debieran ser concedidos con fuerte condicionalidad, a la usanza del FMI. Incluso sería con-

\footnotetext{
${ }^{8}$ En otro trabajo (Agosin, 1999), hemos argumentado que el FMI, para enfrentar crisis agudas en el sistema financiero internacional, podría recurrir a emisiones extraordinarias de DEG, los que se extinguirían al volver el sistema a la normalidad. La mera existencia de dicha posibilidad haría menos probable las crisis sistémicas.
}

cebible que el fondo regional actuara en forma concertada con el FMI en estos casos.

\section{c) Servicio de crédito contingente}

La existencia de este servicio tendría dos objetivos: disuadir a potenciales especuladores y persuadir a los países miembros de que coordinen sus políticas económicas en forma más efectiva.

Si se lo diseña bien, el uso de este servicio sería poco frecuente. Se activaría cuando un país experimentara una crisis de balanza de pagos asociada a una fuga de capitales que no dijera relación con un desequilibrio macroeconómico fundamental. El FLAR tiene en la actualidad un servicio de crédito contingente, recientemente aprobado. Pero el plazo que da para reintegrar los préstamos (seis meses) es demasiado corto y los recursos de que dispone son demasiado exiguos.

Para evitar problemas de riesgo moral, los países miembros tendrían que cumplir con condiciones $e x$ ante mínimas para acceder a este servicio. Ellas podrían incluir avances hacia la regulación bancaria, particularmente en lo que se refiere a los potenciales descalces de monedas entre activos y pasivos; indicadores de fragilidad financiera (razones de deuda de corto plazo a reservas y de reservas a M2), y metas para el déficit en cuenta corriente.

Es importante que no se le agreguen demasiadas dimensiones a estos requisitos previos. El mero hecho de que un país pierda acceso al servicio podría desencadenar una fuga de capitales. Por lo tanto, si bien es imposible evitar algún grado de condicionalidad $e x$ ante, el fondo debiera tener libertad para manejarla con flexibilidad y ambigüedad constructiva.

Para que el servicio pueda ser útil en detener los efectos de manada en los mercados internacionales, los desembolsos debieran ser expeditos. Con tasas de interés más elevadas que para otras operaciones del fondo se incentivaría a los países usuarios a reintegrar los recursos en el período más corto posible.

\section{d) Servicio de financiamiento compensatorio}

Este servicio se activaría cuando un país esté enfrentando problemas de balanza de pagos debidos a un deterioro transitorio y reversible de sus términos del intercambio. Por lo tanto, cuando éstos mejorasen, los países tendrían la obligación de pagar los créditos insolutos y/o de prestar recursos al fondo. El Fondo podría manejar una cuenta especial para este servicio. Los países deudores pagarían interés y los acreedores lo recibirían. Una opción sería incorporar a este servicio, tal como lo hace el FMI, el financiamiento de ne- 
CUADRO 3

América Latina (10 países): Coeficientes de correlación entre variaciones en los términos del intercambio, 1981-1999a

\begin{tabular}{|c|c|c|c|c|c|}
\hline & Argentina & Bolivia & Brasil & Chile & Colombia \\
\hline Bolivia & 0.62 & & & & \\
\hline Brasil & -0.14 & -0.55 & & & \\
\hline Chile & 0.01 & -0.21 & 0.46 & & \\
\hline Colombia & 0.44 & 0.40 & 0.05 & -0.01 & \\
\hline Costa Rica & -0.22 & -0.39 & 0.51 & 0.17 & 0.46 \\
\hline Ecuador & 0.70 & 0.89 & -0.67 & -0.21 & 0.31 \\
\hline Perú & 0.15 & -0.22 & 0.47 & 0.82 & -0.21 \\
\hline Uruguay & 0.10 & -0.10 & 0.16 & 0.70 & -0.25 \\
\hline \multirow[t]{2}{*}{ Venezuela } & 0.61 & 0.84 & -0.60 & -0.10 & 0.08 \\
\hline & Costa Rica & Ecuador & Paraguay & Perú & Uruguay \\
\hline Ecuador & -0.44 & & & & \\
\hline Perú & -0.02 & -0.15 & 0.25 & & \\
\hline Uruguay & -0.13 & 0.17 & 0.16 & 0.53 & \\
\hline Venezuela & -0.67 & 0.91 & -0.20 & 0.02 & 0.04 \\
\hline
\end{tabular}

Fuente: CEPAL, 1999.

a Los coeficientes significativamente distintos de cero aparecen en negrita.

cesidades asociadas a las alzas de las tasas de interés internacionales.

Casi todos los países latinoamericanos sufren fluctuaciones pronunciadas en los términos de su intercambio, ya sea porque los precios de los productos que exportan son volátiles o porque lo son los precios de algunos productos específicos de importación (especialmente el petróleo y los cereales). Los ciclos de los términos del intercambio no están sincronizados entre países. Más aún, los movimientos de algunos precios claves (del petróleo, por ejemplo) simultáneamente mejoran los términos del intercambio de algunos países y deterioran los de otros. ${ }^{9}$

Por lo tanto, es posible y deseable que exista un fondo regional para ayudar a los distintos países a enfrentar los problemas de balanza de pagos derivados de esta condición estructural de sus economías. Al existir compensaciones entre países cuyos términos de

\footnotetext{
${ }^{9}$ Esto ocurre no sólo porque algunos países son exportadores y otros importadores netos de petróleo. Existe también un efecto indirecto sobre los precios de otros insumos industriales. Cuando aumenta el precio del petróleo, las exportaciones de otras materias primas (cobre, hierro, madera) pueden experimentar caídas en los precios de sus exportaciones, si el aumento en el precio del petróleo da lugar a expectativas de que la actividad económica en los países

${ }^{10} \mathrm{Al} 10$ por ciento de significación. Se utilizó el estadígrafo $z=\frac{\hat{\rho} \sqrt{n-2}}{\sqrt{1-\hat{\rho}^{2}}}$, que tiene una distribución $\mathrm{t}$, con $\mathrm{n}-2$ grados de libertad. $\hat{\rho}$ es el valor estimado del coeficiente de correlación.
}

intercambio se deterioran y otros que experimentan mejorías en los suyos, un fondo regional podría hacer un uso mucho más económico de las divisas que los fondos de estabilización que manejan algunos países para estos propósitos. Los países que ya cuentan con dichos fondos podrían aportar parte de los depósitos acumulados en ellos al fondo regional. Como ya se dijo, estos aportes serían adecuadamente remunerados.

Los movimientos en los términos del intercambio no están, en general, correlacionados entre los países de la región, haciendo financieramente viable que una entidad regional opere un esquema como el sugerido aquí. Para el período 1981-1999 se calcularon 55 coeficientes de correlación entre las variaciones anuales en los términos del intercambio de pares de países considerados a la vez. De ellos, sólo 18 resultaron ser significativamente distintos de cero. ${ }^{10}$ Cuatro de los 18 coeficientes fueron negativos; todos ellos involucraban a un país exportador y a un país importador de hidrocarburos (Bolivia-Brasil, Brasil-Ecuador, Brasil-Venezuela y Costa Rica-Venezuela). Tres de los coeficientes de correlación positivos y significativamente distintos de cero se dieron entre países exportadores de hidrocarburos (Bolivia-Venezuela, Ecuador-Venezuela y Bolivia-Ecuador) y uno de ellos entre exportadores de cobre (Chile-Perú). Los resultados se muestran en el cuadro 3, con los coeficientes significativamente distintos de cero resaltados en negrita. 
Un servicio regional de financiamiento compensatorio podría coordinar sus actividades con el servicio homólogo del FMI. De ser esto posible, el fondo regional podría movilizar mayores recursos y contribuir a que los países de la región hicieran más uso del servicio del FMI.

\section{Coordinación de política económica y de supervisión bancaria}

Una institución monetaria regional podría convertirse en un foro adecuado y probablemente muy eficaz para coordinar las políticas económicas de los países de la región con miras a propiciar que los países miembros mantengan los equilibrios macroeconómicos fundamentales para así minimizar la probabilidad de crisis financieras. La coordinación de políticas, que incluiría aquellas relativas a los flujos de capital, es más fácil y aceptable entre pares que cuando es impuesta desde una institución lejana y percibida como hostil. Por lo tanto, un mecanismo financiero latinoamericano fortalecido mejoraría los equilibrios macroeconómicos de los miembros y, por esta vía, los haría menos susceptibles al contagio.

Una mayor convergencia de las políticas económicas, conjuntamente con la existencia de un fondo financiero regional que tuviera acceso a importantes recursos, favorecería la estabilidad cambiaria regional y permitiría avanzar hacia una integración mayor de las economías latinoamericanas.

La debilidad de la supervisión bancaria nacional ha sido una de las causas - aunque ciertamente no la única- de las crisis financieras nacionales. Entre otras falencias, los organismos reguladores no han sabido - o no han podido- impedir que los bancos nacionales se endeuden de manera excesiva en moneda extranjera para luego prestar a entidades que no tienen ingresos en divisas. Un organismo financiero regional puede contribuir a elevar sustancialmente los estándares de supervisión prudencial de sus miembros. Como ya se mencionó, contar con estándares apropiados (y asegurar que se cumplan) puede ser una de las condiciones ex ante para acceder a recursos del servicio de crédito contingente. Asimismo, el organismo podría instituir evaluaciones periódicas de la supervisión bancaria nacional y establecer estándares que pudiesen ser adoptados por todos sus miembros.

La existencia de un fondo regional también permitiría el intercambio fluido de información sobre las experiencias de los distintos países en lo que toca a políticas para la regulación prudencial de los movimientos de capital. Se facilitaría así el avance hacia políticas consensuadas regionalmente en este importante y delicado tema, lo que contribuiría a aliviar las crisis financieras que, como ya hemos señalado, tienden a ser la consecuencia de entradas excesivas de capital extranjero.

\section{VII}

\section{Factibilidad y tamaño de un fondo regional ampliado}

¿Es factible ampliar la cooperación financiera regional de la manera que estamos sugiriendo en este trabajo? Que lo sea o no, va a depender de la magnitud de las crisis nacionales y del grado de covarianza que exista entre ellas. Si todos los países de la región sufren crisis de balanza de pagos simultáneas por contagio financiero (o por deterioro de los términos del intercambio), un fondo regional podría ser inviable desde el punto de vista financiero.

Para dilucidar los interrogantes sobre la covarianza de las crisis nacionales se hizo un análisis de correlación, considerando dos países a la vez, entre cambios en los flujos de capitales (descontándoles la inversión extranjera directa y los flujos oficiales) en el período 1978-1998 (cuadro 4). El período se dividió en dos subperíodos, 1978-1987 y 1988-1998, para ver hasta qué punto ha aumentado la covarianza entre los flujos de capital a distintos países. En el cuadro 4, los coeficientes de correlación bilaterales que son significativamente distintos de cero al 10 por ciento de significación aparecen en negrita.

Este análisis reveló que, efectivamente, hay bastante covarianza entre los flujos de capital a distintos países latinoamericanos, pero ella no es tan elevada 
CUADRO 4

América Latina (10 países): Coeficientes de correlación entre las entradas netas de capital, 1978-1998 ${ }^{a b}$

\begin{tabular}{|c|c|c|c|c|c|}
\hline \multicolumn{6}{|c|}{ 1978-1998 } \\
\hline & Argentina & Bolivia & Brasil & Chile & Colombia \\
\hline Bolivia & 0.02 & & & & \\
\hline Brasil & 0.30 & -0.20 & & & \\
\hline Chile & 0.22 & -0.49 & 0.41 & & \\
\hline Colombia & 0.50 & -0.07 & 0.61 & 0.29 & \\
\hline Costa Rica & 0.54 & -0.07 & 0.38 & 0.17 & 0.13 \\
\hline Paraguay & 0.58 & -0.01 & 0.51 & 0.34 & 0.37 \\
\hline Perú & 0.58 & -0.43 & 0.62 & 0.61 & 0.40 \\
\hline Uruguay & 0.29 & 0.05 & 0.26 & 0.45 & 0.03 \\
\hline \multirow[t]{2}{*}{ Venezuela } & 0.04 & 0.13 & -0.09 & 0.16 & -0.39 \\
\hline & Costa Rica & Ecuador & Paraguay & Perú & Uruguay \\
\hline Ecuador & 0.66 & & & & \\
\hline Paraguay & 0.47 & 0.45 & & & \\
\hline Uruguay & 0.27 & 0.32 & 0.38 & 0.30 & \\
\hline Venezuela & 0.15 & 0.37 & 0.25 & 0.00 & 0.08 \\
\hline \multicolumn{6}{|c|}{ 1978-1987 } \\
\hline & Argentina & Bolivia & Brasil & Chile & Colombia \\
\hline Bolivia & -0.20 & & & & \\
\hline Brasil & 0.27 & -0.23 & & & \\
\hline Chile & 0.41 & $-\mathbf{0 . 5 7}$ & 0.39 & & \\
\hline Colombia & -0.19 & -0.29 & 0.42 & 0.46 & \\
\hline Costa Rica & 0.67 & 0.26 & 0.42 & 0.11 & -0.11 \\
\hline Ecuador & 0.65 & -0.05 & 0.75 & 0.35 & 0.07 \\
\hline Paraguay & 0.36 & 0.00 & 0.42 & 0.58 & 0.19 \\
\hline Perú & 0.32 & -0.76 & 0.55 & 0.75 & 0.43 \\
\hline Uruguay & 0.38 & 0.06 & 0.11 & 0.45 & -0.37 \\
\hline Venezuela & 0.71 & 0.29 & 0.13 & 0.17 & -0.38 \\
\hline Ecuador & 0.83 & & & & \\
\hline Paraguay & 0.30 & 0.44 & & & \\
\hline Perú & 0.05 & 0.33 & 0.56 & & \\
\hline Uruguay & 0.13 & 0.30 & 0.36 & 0.04 & \\
\hline Venezuela & 0.88 & 0.62 & 0.22 & -0.08 & 0.43 \\
\hline \multicolumn{6}{|c|}{ 1988-1998 } \\
\hline & Argentina & Bolivia & Brasil & Chile & Colombia \\
\hline Bolivia & 0.51 & & & & \\
\hline Brasil & 0.36 & 0.33 & & & \\
\hline Chile & 0.33 & 0.47 & 0.44 & & \\
\hline Colombia & 0.60 & 0.18 & 0.88 & 0.33 & \\
\hline Costa Rica & 0.65 & 0.06 & 0.13 & -0.01 & 0.33 \\
\hline Ecuador & 0.36 & 0.07 & 0.33 & 0.27 & 0.39 \\
\hline Paraguay & 0.62 & 0.82 & 0.57 & 0.15 & 0.51 \\
\hline Perú & 0.71 & 0.80 & 0.63 & 0.52 & 0.52 \\
\hline Uruguay & 0.60 & 0.55 & 0.73 & 0.33 & 0.60 \\
\hline \multirow[t]{2}{*}{ Venezuela } & -0.10 & 0.38 & -0.43 & 0.14 & -0.41 \\
\hline & Costa Rica & Ecuador & Paraguay & Perú & Uruguay \\
\hline Ecuador & -0.24 & & & & \\
\hline Paraguay & 0.13 & 0.30 & & & \\
\hline Perú & 0.51 & 0.12 & 0.76 & & \\
\hline Uruguay & $\mathbf{0 . 5 7}$ & 0.17 & 0.67 & 0.92 & \\
\hline Venezuela & -0.56 & -0.06 & 0.10 & -0.22 & -0.56 \\
\hline
\end{tabular}

Fuente: FMI, 1999.

a Excluidos los flujos de inversión extranjera directa y los flujos oficiales.

b Los coeficientes de correlación bilaterales significativamente distintos de cero al $10 \%$ aparecen en negrita. 
como para hacer financieramente inviable un fondo regional. En 1988-1998, sólo 22 de 55 coeficientes de correlación fueron significativamente distintos de cero y positivos. Otra conclusión que puede avalar la necesidad de contar con un fondo regional es el aumento que ha experimentado en el tiempo el número de correlaciones bilaterales elevadas: las correlaciones positivas y significativamente distintas de cero aumentaron de 11 a 22 entre 1978-1987 y 1988-1998, mientras que las negativas (y significativas) se mantuvieron constantes en dos.

Con el objeto de establecer el orden de magnitud que debiera tener un fondo regional, también se examinaron los cambios anuales en los flujos de capital privados -excluyendo la inversión extranjera directa (IED) - a los seis países más grandes de la región, salvo México, en el período 1991-1998. Si las salidas anuales se producen simultáneamente de todos los países, es poco probable que un fondo regional pueda hacerles frente. En el cuadro 5 se puede advertir una tendencia a que tanto los aumentos como las disminuciones de los capitales extranjeros privados estén correlacionados entre los países. Sin embargo, hay suficiente divergencia en las situaciones individuales como para que un fondo regional sea viable. Por ejemplo, mientras en Argentina había grandes necesidades de financiamiento en 1994 debido a la "crisis del tequila", Brasil exhibía cuantiosas entradas de capital. Exactamente lo contrario ocurrió en 1997-1998. Las mayores necesidades de financiamiento se registraron en 1994-1995 y 1997-1998. El monto máximo de dichas necesidades puede estimarse como la suma de las cifras negativas en el cuadro 5. En estos años de crisis, dichas cifras se ubicaron entre 25 y 30 mil millo- nes de dólares, ciertamente abordables por un fondo regional.

Es importante considerar que la existencia de un fondo regional con capacidad para enfrentar crisis podría resultar en un cambio de régimen: al detener una crisis en un país, la probabilidad de que ella se extienda a otros países podría disminuir considerablemente. En otras palabras, la existencia del fondo reduciría la covarianza de los flujos de capital a los países de la región.

Si es efectivo que las crisis son secuenciales, y que la existencia de un fondo de dimensión adecuada disminuiría la probabilidad de contagio a otros países de la región, el fondo debiera tener suficientes recursos como para que un país miembro vulnerable y con capacidad para generar contagio pudiera enfrentar la no renovación de su deuda de corto plazo. Un fondo que contara, digamos, con un $15 \%$ de las reservas (en 1997, el último año "normal" para la región en su conjunto) de los 11 países incluidos en el cuadro 6 (unos 20 mil millones de dólares), podría cubrir cómodamente fugas de capitales equivalentes a toda la deuda de corto plazo de cada país del grupo, excepto la de Brasil. Para enfrentar posibilidades de fugas de capital simultáneas desde más de un país, líneas de crédito contingentes como las sugeridas más arriba dotarían al fondo de una capacidad financiera aun mayor.

La primera línea de defensa en contra de las fugas de capital son las reservas propias. Como también se observa en el cuadro 6, los países latinoamericanos son bastante prudentes en este sentido, ya que en casi todos ellos las reservas en 1997 superaban con holgura el total de su deuda de corto plazo, lo que no suce-

CUADRO 5

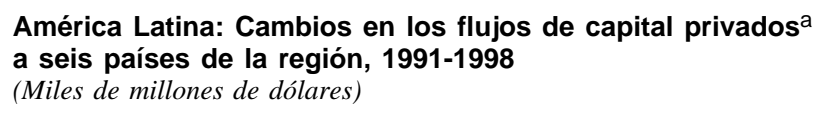

\begin{tabular}{rrrrrrrr}
\hline & Argentina & Brasil & Chile & Colombia & Perú & Venezuela $^{\text {Suma }}$ \\
\hline 1991 & 5.6 & 0.7 & -2.3 & -0.6 & -0.2 & -12.8 & -15.8 \\
1992 & 3.9 & 9.0 & 1.6 & 0.6 & 1.1 & -0.5 & -0.0 \\
1993 & 26.2 & 2.7 & 0.2 & 2.9 & -0.5 & -1.4 \\
1994 & -21.6 & 31.5 & 0.1 & 0.2 & 0.5 & -5.3 & -26.9 \\
1995 & -11.6 & -15.3 & -1.6 & 1.1 & 0.1 & 1.3 & -28.5 \\
1996 & 8.7 & 1.7 & 1.2 & 0.0 & -0.5 & 0.4 & -0.5 \\
1997 & 1.4 & -18.4 & -1.0 & -3.2 & 2.3 & -1.0 & -2.0 \\
1998 & 4.0 & -20.9 & -4.6 & 0.6 & -2.7 & 0.8 & 28.2 \\
\hline
\end{tabular}

Fuente: FMI, 1999.

a Excluyendo a la inversión extranjera directa.

b De las disminuciones de financiamiento privado. 
CUADRO 6

América Latina (11 países): Reservas internacionales, deuda de corto plazo y cantidad de dinero, 1997

(Miles de millones de dólares)

\begin{tabular}{lccrr}
\hline & Reservas internacionales & Deuda de corto plazo & Cantidad de dinero (M1) & Cantidad de dinero (M2) \\
\hline Argentina & 22.8 & 18.0 & 21.5 & 77.6 \\
Bolivia & 1.2 & 0.4 & 0.7 & 3.8 \\
Brasil & 52.0 & 36.2 & 47.3 & 236.5 \\
Chile & 17.7 & 9.9 & 7.7 & 33.6 \\
Colombia & 9.7 & 5.7 & 10.3 & 24.9 \\
Costa Rica & 1.3 & 0.5 & 1.5 & 4.0 \\
Ecuador & 2.2 & 2.1 & 0.9 & 6.7 \\
Paraguay & 0.7 & 0.5 & 5.7 & 2.9 \\
Perú & 11.3 & 6.8 & 1.1 & 16.8 \\
Uruguay & 1.7 & 1.9 & 11.4 & 8.6 \\
Venezuela & 15.2 & 4.4 & & 19.0 \\
Total & 135.8 & & & \\
\hline
\end{tabular}

Fuentes: Banco Mundial (1999) y FMI (1999).

dió en los países asiáticos en la última crisis. Sin embargo, es necesario tomar en cuenta que, en una crisis, las fugas de capital tienen otros componentes, como la liquidación de inversiones extranjeras de cartera y la sustitución por parte de inversionistas nacionales de activos en moneda nacional por otros denominados en moneda extranjera.

En situaciones de crisis, la dimensión máxima de las presiones sobre la balanza de pagos está dada por la cantidad de dinero. Si los agentes pierden totalmente la confianza en una economía, buscarán convertir una alta proporción de sus activos líquidos en divisas. Esos activos líquidos están determinados por los acervos de dinero nacional, que para estos fines podemos medir como M1 (monedas y billetes en circulación más depósitos a la vista) o M2 (M1 más depósitos a plazo y depósitos de ahorro). Las cifras correspondientes también se muestran en el cuadro 6 .
El 15\% de las reservas de los 11 países allí considerados asciende a 20.4 mil millones de dólares. Esto indica que todos ellos, salvo Brasil y Argentina, podrían enfrentar una fuga de capitales equivalente a la totalidad de su M2 con reservas propias (85\% de la cifra indicada en el cuadro 6 como reservas internacionales) y las de un fondo constituido con el $15 \%$ de las reservas de los 11 países en conjunto. Argentina, por su parte, podría financiar salidas de capital equivalentes a todo su M1 y más de la mitad de su M2. Dicho de otra manera, un fondo con $15 \%$ de las reservas representa un potencial importante para disuadir ataques especulativos en contra de las monedas de los países de la región. Si se le pudieran agregar otras fuentes de financiamiento, como las sugeridas más arriba, el fondo propuesto podría desempeñar un importante papel en la promoción de la estabilidad de las economías latinoamericanas.

\section{VIII}

\section{Conclusiones}

En este artículo se ha argumentado a favor de la creación de un fondo regional que contribuya a llenar un vacío en la arquitectura financiera internacional. Tal fondo sería de gran utilidad para los países de la región como línea adicional de defensa ante las crisis financieras internacionales, que se han vuelto cada vez más exógenas a las políticas nacionales y que probablemente continuarán golpeando a la región aun cuando los países continúen mejorando la calidad de sus políticas macroeconómicas.

Por supuesto, un fondo regional no puede sustituir a la prudencia macroeconómica. Más bien, su 
existencia contribuiría a que los países de la región fuesen mejorando la calidad de sus políticas macroeconómicas. Un fondo con recursos importantes para prestar a países que pongan en práctica buenas políticas sería un incentivo poderoso en esa dirección.

El fondo regional puede concebirse en el marco de una reforma profunda de la estructura financiera actual o como un organismo que se inserte en un sistema que no sufriría variaciones fundamentales. Aunque el primer escenario es el más favorable desde el punto de vista de la eficiencia del nuevo organismo para proteger a los países de la región de los efectos adversos de turbulencias financieras internacionales, en el segundo escenario dicho fondo sería aun más necesario. Por lo demás, como hemos argumentado en la sección anterior, el fondo regional no está fuera del alcance de las capacidades financieras de los países latinoamericanos en las circunstancias actuales.

Un fondo regional como el propuesto tendría la misión adicional, de gran importancia para el desarrollo futuro de la región, de contribuir a la integración de la economía regional a través de la promoción de la estabilidad cambiaria y la coordinación de políticas macroeconómicas. En sus políticas para promover la integración regional, hasta ahora los países han privilegiado el avance hacia la armonización de las políticas comerciales. Las barreras comerciales entre ellos han tendido a disminuir significativamente en la última década, y los retrocesos que se han observado han estado casi siempre relacionados con turbulencias financieras. En algunos casos, los gobiernos han tenido que recurrir a la protección comercial para defenderse de los efectos de entradas de capital que aprecian el tipo de cambio y amenazan a actividades nacionales transables en el ámbito internacional. En otros, la fuga de capitales provoca crisis de balanza de pagos que no dejan más alternativa que restringir los flujos comerciales. Definitivamente, la mayor amenaza que se cierne sobre el progreso de la integración regional es la inestabilidad financiera internacional, que ha acrecentado significativamente la volatilidad cambiaria y la inestabilidad interna de los países de la región.

El mecanismo institucional propuesto podría amortiguar los efectos adversos de la inestabilidad financiera internacional sobre las economías nacionales y, además, contribuir a que los países puedan avanzar hacia la integración económica. Con cada crisis financiera de las que azotan periódicamente a los países de la región, los avances en materia de integración que se logran con mucho esfuerzo suelen ser sucedidos por retrocesos parciales. Una mayor estabilidad de los tipos de cambio y de las economías internas permitiría a los países de América Latina converger hacia la deseada integración comercial, sueño nacido hace cuatro décadas y aún no realizado.

\section{Bibliografía}

Agosin, M. R. (1999): Towards a New Architecture for the International Financial System: Lessons from the Financial Crisis, Documento de trabajo $\mathrm{N}^{\circ} 1$, Santiago de Chile, Universidad de Chile, Departamento de Economía, Centro de Economía Internacional y Desarrollo (CENDES).

Agosin, M. R. y R. Ffrench-Davis (1997): Managing capital inflows in Chile, Estudios de Economía, vol. 24, N ${ }^{\circ}$ 2, Santiago de Chile, Universidad de Chile, Departamento de Economía.

Ahluwalia, M. S. (2000): Reforming the Global Financial Architecture, Secretaría del Commonwealth, Londres, abril.

Banco Mundial (1999): Global Development Finance, Country Tables, 1999, Washington, D.C.

Barrera, R. y M. Cárdenas (1997): On the effectiveness of capital controls: the experience of Colombia during the 1990s, Journal of Development Economics, vol. 54, № 1, Amsterdam, Países Bajos, Elsevier Science Publishers, B.V.

Calvo, G., L. Leiderman y C. Reinhart (1993): Capital Inflows and Real Exchange Rate Appreciation in Latin America: The Role of External Factors, IMF Staff Papers, vol. 40, No 1 , Washington, D.C., Fondo Monetario Internacional (FMI).

CEPAL (Comisión Económica para América Latina y el Caribe) (1990): La cooperación regional en los campos financiero y monetario, Serie Financiamiento del Desarrollo, $N^{\circ} 5$, Santiago de Chile.
(1999): Balance preliminar de las economías de América Latina y el Caribe, LC/G.2088-P, Santiago de Chile.

Devlin, R., R. Ffrench-Davis y S. Griffith-Jones (1995): Repunte de las corrientes de capital y el desarrollo: implicaciones para las políticas económicas, en R. Ffrench-Davis y S. GriffithJones (eds.), Las nuevas corrientes financieras hacia la América Latina. Fuentes, efectos y políticas, Santiago de Chile, CEPAL/Fondo de Cultura Económica (FCE).

Eatwell, J. (1997): International capital liberalization: The impact on world development, Estudios de Economía, vol. 24, $\mathrm{N}^{\circ} 2$, Santiago de Chile, Universidad de Chile, Departamento de Economía.

Eichengreen, B. (1999): Toward a New International Financial Architecture, Washington, D.C., Institute for International Economics.

FLAR (Fondo Latinoamericano de Reservas) (1998): Memoria Anual, 1997-1998, Santafé de Bogotá.

(2000): Propuesta para la transformación del Fondo Latinoamericano de Reservas en un fondo monetario latinoamericano, Santafé de Bogotá, marzo.

FMI (Fondo Monetario Internacional) (1998): Estadísticas financieras internacionales, Anuario 1998, Washington, D.C.

(1999): Estadísticas financieras internacionales, Anuario 2000, Washington, D.C. 
Kaminsky, G. y C. M. Reinhart (1996): The Twin Crises: the Causes of Banking and Balance of Payments Problems, International finance discussion paper, $\mathrm{N}^{\circ} 544$, Washington, D.C., Junta de Gobernadores de la Reserva Federal, marzo.

Kaminsky, G., S. Lizondo y C.M. Reinhart (1998): Leading Indicators of Currency Crises, IMF Staff Papers, vol. 45, $\mathrm{N}^{\circ} 1$, Washington, D.C., FMI.

Krugman, P. (1979): A model of balance of payments crises, Journal of Money, Credit, and Banking, vol. 11, $\mathrm{N}^{\circ} 3$, Columbus, Ohio, Ohio State University.

Le Fort, G. y S. Lehmann (2000): El encaje, los flujos de capitales y el gasto: Una evaluación empírica, Documento de trabajo, $N^{\circ}$ 64, Santiago de Chile, Banco Central de Chile, febrero.

Mistry, P. S. (1999): Coping with financial crises: Are regional arrangements the missing link?, en UNCTAD (Conferencia de las Naciones Unidas sobre Comercio y Desarrollo), Interna- tional Monetary and Financial Issues for the 1990s, vol. 10, Ginebra .

Ocampo, J. A. (1999): La reforma del sistema financiero internacional: un debate en marcha, Santiago de Chile, Fondo de Cultura Económica.

Ocampo, J. A., y R. Steiner (1994): Los capitales extranjeros en las economías latinoamericanas, en J. A. Ocampo (ed.), Los capitales extranjeros en las economías latinoamericanas, Santafé de Bogotá, Fundación para la Educación Superior y el Desarrollo (FEDESARROLLO)/Banco Interamericano de Desarrollo (BID).

Ocampo, J. A., y C. Tovar (1999): Price-based Capital Account Regulations: the Colombian Experience, Serie Financiamiento del desarrollo, $\mathrm{N}^{\circ}$ 87, Santiago de Chile, CEPAL.

Rodrik, D., y A. Velasco (1999): Short-term capital flows, ABCDE Conference, Washington, D.C., Banco Mundial. 